\title{
Preparation of MOF-based Nitrogen Self-Doped Porous Carbon and Its Electrochemical Properties
}

\author{
Zhijian Zhang ${ }^{1}$, Pitao Wang $^{2}$, Chi Zhang ${ }^{2}$, Shuai Li ${ }^{2}$, Jianqiang Zhang ${ }^{2, *}$, and Heming Luo ${ }^{2, *}$ \\ ${ }^{1}$ School of Material Science and Engineering, Lanzhou University of Technology, Lanzhou, 730050, \\ P.R. China \\ ${ }^{2}$ School of Petrochemical Engineering, Lanzhou University of Technology, Lanzhou, 730050, P.R. \\ China \\ *E-mail: 1uohm666@163.com
}

doi: $10.20964 / 2021.03 .52$

Received: 7 November 2020 / Accepted: 28 December 2020 / Published: 31 January 2021

\begin{abstract}
Metal-organic frameworks (MOFs) are widely used as precursors to prepare porous carbon materials due to their highly ordered porous structure and large specific surface area. In this paper, a metal-organic framework $\left\{\left[\mathrm{Zn}(1,4-\mathrm{BDC})_{0.5}\left(3-\mathrm{NH}_{2} \text {-trz) }\right] \text {. (solvent) }\right\}_{\mathrm{n}}\right.$ was prepared using a solvent method as a precursor to prepare nitrogen self-doped porous carbon ZAPC-T by a direct carbonization, and the effect of different carbonization temperatures on the microstructures, compositions, and electrochemical properties of the nitrogen self-doped porous carbon ZAPC-T samples was investigated. Results showed that the specific surface area of ZAPC-800 reached $728.57 \mathrm{~m}^{2} \mathrm{~g}^{-1}$ with nitrogen and oxygen contents of $19.09 \%$ and $5.93 \%$, respectively. When the carbonization temperature was $800{ }^{\circ} \mathrm{C}$, the specific capacitance of ZAPC-800 was $225.4 \mathrm{~F} \mathrm{~g}^{-1}$ at a current density of $1.0 \mathrm{~A} \mathrm{~g}^{-1}$, and after 5000 cycles, the capacitance retention was as high as $83.01 \%$ with constant current charging and discharging. The specific capacitance decay rate was only $21.2 \%$ when the current density was increased from $1.0 \mathrm{~A} \mathrm{~g}^{-1}$ to $10.0 \mathrm{~A} \mathrm{~g}^{-1}$. Thus, nitrogen self-doped porous carbon ZAPC-800 showed excellent electrochemical properties and good cycling stability. This study provides useful experimental data for the preparation of MOF-based nitrogen self-doped porous carbons and their applications.
\end{abstract}

Keywords: supercapacitor; metal-organic frameworks; hydrothermal method; nitrogen self-doped porous carbon; electrochemical

\section{$\underline{\text { FULL TEXT }}$}

(C) 2021 The Authors. Published by ESG (www.electrochemsci.org). This article is an open access article distributed under the terms and conditions of the Creative Commons Attribution license (http://creativecommons.org/licenses/by/4.0/). 